\title{
A PASSAGEM DO "EU PENSO" AO "EU EXISTO" EM JAAKKO HINTIKKA E EM JACQUES LACAN"
}

\author{
Léa Silveira Sales
}

Professora substituta do Departamento de Filosofia da UFSCar. Doutoranda em filosofia da UFSCar.

RESUMO: Apesar de validar o cogito no ato da enunciação, o interesse que Lacan nele deposita se distancia da autoverificabilidade existencial da proposição "eu existo", tal como defendida por Jaako Hintikka. Embora ambos os autores assumam a necessidade de remeter o ato da representação a algo além do nível da representação (a qualificação performativa do cogito), se, para o primeiro, a força do argumento cartesiano concentra-se na proposição "eu existo", na medida que saberíamos a quem este "eu" encontrar-se-ia referido, para o psicanalista, essa é justamente a proposição ameaçada de invalidação e, tal saber, aquele que deve ser questionado.

Palavras-chave: Lacan, Descartes, Hintikka, cogito, sujeito.

ABSTRACT: The passage from "I think" to "I exist" in Jaakko Hintikka and in Jacques Lacan. Although Lacan validates the cogito in the act of enunciation, the interest that he deposits in it is far from the existential auto-verifiability of the proposition "I exist" as sustained by Jaako Hintikka. Even if both of them assume the need of referring the act of representation to something beyond the level of representation (the performative qualification of the cogito), while the philosopher concentrates the power of the Cartesian argument om the proposition "I exist" - for we would know to whom this "I" would be refered to - , to the psychoanalyst this is exactly the proposition which is threatened by invalidation and, such knowledge, the one that must be questioned.

Keywords: Lacan, Descartes, Hintikka, cogito, subject.

\footnotetext{
* Esse trabalho foi apresentado no II Encontro Nacional de Pesquisadores em Filosofia e Psicanálise: A Filosofia após Freud, realizado na Universidade de São Paulo, em 2006.
} 
0 problema da passagem do "eu penso" ao "eu existo", sobre o qual se fundamenta toda a estrutura do cogito — e, consequentemente, toda a estrutura da filosofia cartesiana - tem seus impasses explorados desde o momento mesmo de sua enunciação original. Qual o artifício que realmente garantiria a legitimidade de tal passagem? Trata-se de uma inferência lógica, de uma percepção imediata, de alguma espécie de intuição? De onde ela retira a força que conduz a afirmação a apresentar essa atmosfera de verdade irrefutável? O fato de ter sido enunciada em primeira pessoa é contingente ou necessário? Por que o verbo cogitare - aliás, com sentido bem mais amplo que o nosso atual "pensar" - assume essa espécie de privilégio diante da afirmação da existência? Ou seja, por que o dispositivo não pode também se valer de estruturas tais como "caminho, logo sou" ou "vejo, logo sou” conforme propõem as conhecidas objeções de Gassendi e Hobbes? Essas são algumas das questões clássicas sugeridas pelo argumento cartesiano e inseparáveis de tudo o que o pensamento atual deve à filosofia moderna.

A dificuldade maior deve-se ao fato de que a aplicação metódica da dúvida - pelos sucessivos argumentos dos erros dos sentidos, do sonho, da loucura e do Gênio Maligno - exclui, para os fins de asserção de uma certeza primeira, qualquer apoio que ela pudesse reivindicar nos sentidos ou no próprio uso ordinariamente epistêmico da razão. Descartes diz que ela é vista "por uma simples inspeção do espírito”. Dito de outro modo, o problema é: como explicar, com os instrumentos da razão, a legitimidade de uma operação cuja condição de funcionamento é justamente que ela escape, de certa forma, ao domínio mais evidente de tais instrumentos? Ou seja, se a dúvida hiperbólica atinge qualquer forma de raciocínio, eliminando a possibilidade do apoio na percepção, na imaginação ou em princípios lógico-matemáticos, como ainda descrever de modo racional o ponto de certeza secretado exatamente por ela e que permite, de acordo com a estratégia cartesiana, alavancar o pensamento rumo a seus próprios critérios de verdade?

O comentário realizado por Jaakko Hintikka (1962) se encaminha pela defesa de que, se o cogito não revela totalmente a lógica de seu funcionamento, tal carência não se deve a equívocos da demonstração, mas justamente a uma impossibilidade lógica. Pois descrever, conforme a lógica, a passagem do "eu penso" ao "eu existo" corresponderia a submetê-la a tudo aquilo que a primeira meditação já demonstrara não sobreviver à aplicação da dúvida metódica. Se esse “tudo" equivale, do início ao fim, ao campo da representação, só resta buscar o que poderia fundamentar um primeiro passo da certeza em algo que se apresente, ao menos provisoriamente, fora desse campo e que, ao mesmo tempo, seja capaz de trazer consigo, de forma imediata, a certeza do existir como correlato do pensar. $\mathrm{O}$ argumento retira seu fôlego da ambiguidade presente no texto de Descartes 
entre, de um lado, sua rejeição categórica a um estatuto silogístico do cogito isso é evidente na medida que lembramos que a premissa maior do silogismo suposto teria que apresentar uma afirmação de ordem epistêmica exatamente do tipo alvejado pelo exercício radical da dúvida ${ }^{1}$ — e, de outro, a indução, em alguns trechos, a entendermos a existência como condição necessária do pensar. Sua originalidade foi defender que a passagem entre uma coisa e outra não precisa nem ser remetida a uma estrutura argumentativa clássica, nem muito menos ser tomada como ponto cego da própria razão, introduzindo, pela noção de performativo - corrente em filosofia analítica e originalmente desenvolvida por Austin — , a ideia de que esse processo externo à representação poderia, sim, ser descrito pelo discurso racional, desde que sejamos capazes de perceber uma dada diferença estratégica entre dois níveis de análise: 1) o nível do que é efetivamente enunciado; 2) o nível das circunstâncias concretas de enunciação, que permite perceber sob que espécie de dispositivo uma frase pode ter seu valor de verdade indissociável das condições lógicas do ato que a pronuncia.

Dessa forma, a representação "eu existo" fica reportada a um ato (SÁ, 2002, p.258-9): o ato de dizer ou pensar "eu penso", na medida que a afirmação, por um dado sujeito, de sua própria não existência produziria uma clara espécie de inconsistência do âmbito de uma contradição performativa. A visada racional das circunstâncias do ato é o que permite a saída do nível estrito e já escusado da representação. É simples entender o argumento de Hintikka a partir de um exemplo. Basta o leitor imaginar que eu, Léa, autora desse texto, tente persuadilo com a seguinte declaração, necessariamente oral: “a Léa não existe”. Ou seja, trata-se de fazer valer a ideia de que um falante, no instante em que fala, não tem como negar sua própria existência, porque tal negação é imediatamente traída pelo ato mesmo que ele executa ao levá-la a termo.

O mesmo truque seria, então, aplicado ao pensamento - de certa forma entendido como fala privada. Isto é: não posso conceber que eu não existo no mesmo momento em que formulo para mim (nesse caso, com ou sem o uso da voz) tal diagnóstico. Por esse motivo, a rigor, Hintikka defende que proferre, e não cogitare, é o verbo mais apropriado para revelar a força do argumento, na medida que ela se encontraria concentrada na autodestrutividade da expressão "eu não existo”. Um tanto quanto ironicamente, ele diz: “Se formos muito exigentes com a exatidão, podemos, então, dizer que Descartes devia ter concluído ergo sum professor ao invés de sum res cogitans" (1962, p.18).

Por esse caminho, Hintikka providencia suas próprias respostas às perguntas com as quais abrimos este artigo. Assim, para ele, o cogito só é verdadeiro enquanto eu o penso ou enuncio, não apenas porque sair desse instante é, neces-

\footnotetext{
${ }^{1}$ A forma dessa premissa seria, por exemplo: "tudo o que pensa existe".
} 
sariamente, ter que passar à estrutura argumentativa que, somente por ser uma estrutura argumentativa, o invalida; mas, sobretudo, porque isso implicaria sua dissociação do ato que o justifica.

Por mais que essa posição já tenha sido criticada (ver, especialmente, PARIENTE, 1987 e 1999), o que nos interessa aqui é a possibilidade, já aventada por outros comentadores (SAFATLE, 2000, e SÁ, 2002), de nela encontrar um contraponto elucidativo de determinados aspectos da abordagem lacaniana do inconsciente. Neste momento, já somos capazes de perceber o quão naturalmente surgiriam eventuais aproximações do comentário do filósofo finlandês com o tratamento que Lacan provê ao cogito. Ora, não encontramos aí certa comunidade de elementos que convergem para a valoração do plano enunciativo? Pois não lemos, sob a regência do psicanalista, algo como: "Digamos que é o fato de tomar seu lugar no nível da enunciação que confere sua certeza ao cogito” (LACAN, 1964/1973, p.157-8)? Não poderíamos tranquilamente atribuir a Hintikka a autoria dessa frase? Aparentemente, não estaria Lacan, inclusive, prontamente de acordo com a substituição do "sou pensante" pelo "sou falante"? Ao tomar da linguística estrutural elementos para a construção de um novo conceito de significante, mantendo, ao mesmo tempo, a absolutamente necessária valorização da dimensão fenomenológica da fala, o inconsciente proposto por Lacan pode começar a ser analisado a partir de um ponto que, tomado exclusivamente neste nível, revela ser exatamente o mesmo - , qual seja, a junção de um ato com uma representação. A princípio, portanto, seja o contraponto motivo de aproximação ou de distanciamento, temos fortes subsídios para supor que há aí, no mínimo, uma interessante discussão a ser desenvolvida.

O que se quer expor aqui são os termos segundo os quais, apesar de tais observações imediatas, a aproximação não resiste a um segundo passo de análise. Isso porque tudo o que fundamenta a defesa de Hintikka pode ser descrito sob duas premissas interdependentes: 1) a sustentação de que o eu do "eu penso" é o mesmo eu do "eu existo"; 2) que conheçamos, como fato incontestável implicado na performance, a identidade do eu enunciador. Se lembrarmos que o contexto do mais disseminado dictum filosófico exigiu a implicação solitária de René Descartes como observador e ouvinte de si mesmo, e que tal percurso deve ser concretamente refeito por todos que intencionem acompanhá-lo, veremos que ambas as premissas expressam, de dois ângulos diferentes, um mesmo postulado: a unidade da consciência como origem da fala e do pensamento.

Hintikka não deixa de lado sua costumeira clareza quando diz que o efeito destrutivo da inconsistência existencial “(...) está obviamente condicionado ao fato de que o ouvinte saiba quem faz a declaração, isto é, que identifique o falante como sendo a mesma pessoa a quem se refere a sentença proferida” (1962, p.13). Não poderia mesmo ser de outro modo: é evidente que a noção 
de inconsistência existencial perde todo o seu sentido se não pressupusermos a identidade do eu nas duas sentenças do cogito. ${ }^{2}$ Detenhamo-nos um instante neste ponto acompanhando uma explicação do autor:

“A noção de inconsistência existencial (...) pode muitas vezes ser aplicada a declarações em um sentido bem natural. A fim de especificar uma declaração, precisamos especificar (...) a sentença proferida (digamos, q) e seu emissor. Se este se refere a si mesmo mediante o único termo b quando produz sua declaração, podemos dizer que a noção se aplica à declaração se, e somente se, ela se aplica a q em relação a b.

Um exemplo simples esclarecerá essa situação. As sentenças 'De Gaulle não existe' e 'Descartes não existe' não são mais inconsistentes ou objetáveis do que a discutível sentença 'Homero não existe'. Nenhuma delas é falsa devido a razões exclusivamente lógicas. O que seria (existencialmente) inconsistente seria a tentativa, por parte de uma certa pessoa (De Gaulle, Descartes ou Homero, respectivamente) de usar uma dessas sentenças para fazer uma declaração. Pronunciadas por outras pessoas, não há forçosamente nada de errado, ou mesmo estranho, com as sentenças em questão.” (1962, p.12)

Guardemos por um instante essas explicações e busquemos apreender, ainda que de modo muito breve, um pouco do sentido do recurso de Lacan a Descartes.

Quando o psicanalista assume a existência de um pensamento inconsciente — interpretado à luz da linguística estrutural — dentro do contexto da eleição do sujeito como sua principal questão, é natural que Descartes lhe apareça como uma passagem necessária. O vínculo entre subjetividade e pensamento exposto pelo cogito lhe interessa na medida que pode fornecer a chave para a dedução da primeira, necessária à discussão da visada ética sempre presente em

\footnotetext{
2 Tal identidade parece ser o caminho sustentado pela maior parte dos comentadores de Descartes. Encontramos, no entanto, a defesa de que ele não é um caminho absolutamente necessário no texto de Lia Levy, 2004. Sendo esse um assunto para outro debate, ressaltemos apenas dois pontos: 1) A autora reduz a análise do quarto parágrafo das Meditações à frase "eu penso que eu existo" com a intenção de relegar a um plano não necessário a questão da reflexividade da consciência. No entanto, tal frase não parece transcrever a lógica do cogito na medida que essa estrutura só foi atingida por meio da dúvida. A base do argumento cartesiano é, antes, "eu duvido; não posso duvidar sem existir", o que recoloca a questão do ato reflexivo. 2) Por outro lado, essa formulação "eu penso que eu existo", traduzindo a percepção que venho a ter de minha própria existência, encontrar-se-ia, tal como qualquer outro ato perceptivo, tranquilamente inserida no campo de aplicação da dúvida; ou seja, "que eu existo" aparece como um mero "conteúdo" do pensamento. De todo modo, ainda que fosse possível distinguir, no texto de Descartes a ausência da necessidade de identificação dos eus, o que nos interessa aqui é que Hintikka se insere na interpretação mais tradicional, supondo-a como condição necessária para a sustentação da primeira certeza.
} 
seu horizonte teórico, desde que tal curso não incorra na substancialização do eu como coisa pensante.

Com relação a esse ponto específico da ilegitimidade da passagem do "eu penso" à afirmação da existência efetiva de um eu, trata-se, em certo sentido, de uma análise fornecida por Kant, ${ }^{3}$ de quem Lacan, muito certamente, acompanha a trilha. Pois, para Kant, ela retira a asserção da substância de uma função puramente lógica, da qual nada se segue em termos existenciais concretos. ${ }^{4}$ Ele concorda com a implicação do "eu existo" no "eu penso", a qual deve ser considerada como uma intuição empírica indeterminada da identidade das duas proposições: o próprio significado de "eu penso" é "eu existo como pensante". O problema é que essa operação necessariamente precede qualquer experiência, impossibilitando, portanto, que a existência em questão seja tomada como categoria - mais exatamente, como a categoria da efetividade, aplicável apenas a objetos sensíveis ligados no tempo. Ou seja, não se trata, aí, de um objeto dado e indeterminado, mas de um objeto sobre o qual apenas formulamos o conceito (ver LONGUENESSE, 2006, p.251-3). A validade do “eu penso” deve-se, assim, não à ordem da experiência, mas a seu lugar necessário na ciência transcendental - todo e qualquer pensamento o exige como condição lógica (a perspectiva da unidade da consciência) para afigurar-se como pensamento. Esse lugar é, portanto, estritamente anterior à experiência. Vejamos mais detidamente como:

“Ora, como a proposição eu penso (...) contém a forma de todo o juízo do entendimento em geral e acompanha todas as categorias, como seu veículo, é claro que as conclusões extraídas dessa proposição só podem conter um uso simplesmente transcendental do entendimento, que exclui qualquer ingerência da experiência (...).” (KANT, 1787/1985, p.331)

Assim, ele não pode gerar nenhum conhecimento como o seria a afirmação existencial empírica do eu. A consciência de mim mesmo como ser pensante é algo que precisa ser muito diferenciado de uma intuição que eu pudesse ter de mim como objeto de conhecimento, a qual, em si mesma, já implicaria a estrutura a priori do pensamento da qual não pode deixar de fazer parte o "eu penso". A autoconsciência é uma função lógica necessária ao conhecimento, mas insuficiente a seu respeito, visto que a ele não fornece nenhum objeto. E, se assim não fornece nenhum objeto, faltando-lhe a contraparte empírica, também não fornece 0

\footnotetext{
${ }^{3}$ Para uma explicação exemplarmente bem detalhada desse problema, ver Longuenesse, 2006.

${ }^{4}$ Sá também comenta que, para Kant, “(...) essa inferência consiste num paralogismo, pois o eu do eu penso consiste numa função enquanto o eu do eu existo introduz a noção de substancialidade que não está presente no eu penso" (SÁ, 2002, p.268).
} 
eu como objeto, sem o que nada se pode inferir acerca de seu modos ou atributos - de sua existência como substância, portanto:

“Em todos os juízos eu sou sempre o sujeito determinante da relação que constitui o juízo. Mas que eu, eu que penso, tenha sempre no pensamento o valor de um sujeito, de algo que não possa ser considerado apenas ligado ao pensamento como predicado, é uma proposição apodítica e mesmo idêntica; não significa, todavia, que eu, enquanto objeto, seja um ser subsistente por mim mesmo ou uma substância." (KANT, $1787 / 1985$, p.334)

Esse segundo passo exigiria a validação de uma proposição sintética que o caráter das ideias transcendentais (psicológicas, cosmológicas e teológicas) somente conceitos puros da razão - não autoriza formular. O silogismo que subsidia o paralogismo da psicologia racional desconsidera a diferença entre o eu como unidade necessária da consciência e o eu como algo que se apresentasse à apreensão pela intuição. Eliminada a confusão, dele seria legítimo deduzir apenas que “(...) não posso, no pensamento da minha existência, servir-me de mim a não ser como sujeito do juízo, que é uma proposição idêntica, que não explica absolutamente nada sobre o modo da minha existência” (KANT, 1787/1985, p.343, grifo nosso). Que eu possa (ou deva) deduzir o eu não significa que eu possa afirmar alguma coisa a respeito da verdade de sua existência concreta.

Sartre comenta esse movimento nomeando de "realização" a tentativa de afirmar algo a respeito da existência efetiva do eu a partir do sujeito transcendental, ressaltando sua impropriedade: “(...) realizar o Eu transcendental, fazer dele o companheiro inseparável de cada uma das nossas 'consciências', é julgar a respeito do fato e não a respeito do direito, é colocar-se num ponto de vista radicalmente diferente do de Kant” (1936/1994, p.44). Retornando a Lacan, diríamos que ele não se coloca fora da questão da realização do eu — e, nesse sentido, ele é mais cartesiano que kantiano. Mas assim o faz para, de modo preciso, desrealizá-lo, com o que imediatamente se afasta de Descartes. Ou seja, ao contrário de Kant, não abre mão, apesar de problematizá-la, da implicação propriamente existencial do cogito. Contudo, na esteira de Kant, entende a inadequação da conclusão pela substância a propósito do eu, o que impede a instauração de um saber a seu respeito. É exatamente isso que está implícito quando Lacan observa que:

"Quando Descartes inaugura o conceito de uma certeza que se apoiaria inteiramente no eu penso da cogitação (...), poder-se-ia dizer que seu erro foi acreditar que haveria aí um saber. Dizer que ele sabe algo a respeito dessa certeza. Não fazer do eu penso um simples ponto de esvanecimento.” (1964/1973, p.204) 
Uma vez que temos aí o evento da certeza de si mesmo como ser desejante, ela, por ser certeza do desejo, não pode gerar nenhum estabelecimento de identidade. A posição do "eu penso" é, assim, sustentada exclusivamente enquanto dura o enunciado, como índice de uma enunciação. Ou melhor, à pergunta de Descartes nas Meditações: “Eu sou, eu existo: isto é certo; mas por quanto tempo?” (1641/1983, p.94), Lacan responderia: por um tempo negativo ou por um instante fora do tempo no qual o sujeito nunca é mais do que suposto, o que impele o cogito a “(...) participar, em seu esforço de certeza, de uma espécie de aborto” (LACAN, 1964/1973, p.129). Aquela percepção do pensar acha-se, portanto, destituída de seu lugar: em vez de ser realizada pelo próprio sujeito que pensa, só pode ser atribuída ao analista que apreende os efeitos do inconsciente ou ao teórico que os põe em questão. Diante das lacunas do discurso, eles poderiam assegurar, ex post facto: "ali havia um sujeito".

Assim, a exemplo de Kant, para quem o eu como condição lógica do pensamento não permite franquear nenhum passo na direção de declarações sobre as características de sua existência de fato, para Lacan, cerzir o modo de existência do eu é uma manobra ilegítima, pois extrapola a única dimensão concreta e imediatamente acessível, que é a da fala. Essa observação aligeirada já sugere, de saída, ao menos duas coisas: que a abordagem lacaniana do cogito não tem, evidentemente, nada a ver com um exercício de história da filosofia; que este conceito precisa ser totalmente repensado diante da hipótese do inconsciente.

O problema, nesse contexto, é manter a dedução do sujeito sob o pensamento - e, para Lacan, o pensamento verdadeiro é o pensamento inconsciente eliminando a percepção de si por si, introduzindo um corte em seu instante. Com efeito, aqui, tal como na dúvida hiperbólica das Meditações, o sujeito, para enunciar a si mesmo, precisa anular sua própria realidade; ele inicia um movimento de apreensão da própria verdade negando a realidade objetiva em função de uma autorrepresentação. A existência do sujeito fica garantida — pois se admite que todo pensamento o pressupõe como lugar e horizonte do sentido — , mas não a percepção reflexiva. Ao apontar o cogito como noção indispensável, Lacan afirma que o deslize foi fazê-lo coincidir com a consciência. Dirá mais tarde, preservando esse raciocínio: "O cogito cartesiano (...) só denuncia melhor o que tem de privilegiado o momento em que ele se apoia, e quão fraudulento é estender seu privilégio, para lhes conferir um status, aos fenômenos providos de consciência” (1960/1966, p.831). Esse erro conduz, consequentemente, o filósofo a igualar o sujeito que fala ao sujeito do qual se fala, criando a ilusão da identidade. A proposta de Lacan é, em contraponto, situar aí uma pergunta: "O lugar que ocupo como sujeito do significante é, em relação ao que ocupo como sujeito do significado, concêntrico ou excêntrico?” (LACAN, 1957/1966, p.516-7); e desdobrar sujeito e objeto em enunciado e enunciação, procurando 
mostrar que quando eu falo de mim, o "eu” e o "mim” não possuem aí o mesmo referente. "Não se trata de saber se falo de mim conforme aquilo que sou, mas se, quando falo de mim, sou o mesmo que aquele de quem falo" (LACAN, 1957/1966, p.517). Fica claro, portanto, que, na proposição "eu penso, eu sou”, a relação entre os dois eus não pode ser de identificação. Enquanto, para Descartes, o segundo eu (o do "eu sou”) traduziria um "Indivíduo que se reassume como o mesmo quando reflete sobre seus diferentes pensamentos (...)" (BEYSSADE, 1974, p.97), para Lacan este eu não passa de uma ilusão imaginária objetivante. Ilusão que não se aplica ao primeiro eu (o do "eu penso"), pois ele é somente uma posição sem implicação de substância, significando apenas que uma vida, reconstituída pelo funcionamento da linguagem, atravessa um pensamento ou uma enunciação. Mas, se o "eu penso" não se submete à ilusão imaginária, não deixa de sofrer, ele mesmo, a incidência da dúvida pois, com isso, impossibilitase o "logo sou”, ou "logo existo", com a ideia de substancialidade que carrega: ele é “(...) reduzido a esta pontualidade de só se garantir pela dúvida absoluta concernente a toda significação, inclusive a sua (...)” (LACAN, 1964/1973, p.158). O que subjaz à colocação em dúvida do próprio sujeito do inconsciente é a noção determinante de significante: sendo definido por sua função de negação, ele impõe ao sujeito uma existência evanescente.

Assim, da proposição "eu penso" segue-se uma afirmação existencial: todo pensamento implica um sujeito como índice de amarração singular do sentido e como origem da ação, ainda que o modo de sua existência seja subvertido. Por outro lado, da proposição “eu existo”, segue-se apenas uma forma de cristalização da existência suposta que, por objetivante, alcança o contrário do que promete, quer dizer, a anulação existencial do sujeito. Por isso, Lacan insiste: “Tudo é permitido ao inconsciente, exceto articular: portanto sou” (1966-1967, p.75, sessão de $21 / 12 / 56)$. Nesse sentido, apesar de validar o cogito no ato da enunciação e de, portanto, indicar para ele uma espécie de interpretação performativa - o interesse que Lacan nele deposita se distancia, em conteúdo e consequências, do comentário de Hintikka quanto à autoverificabilidade existencial da proposição “eu existo”. Apoiando a dedução da presença subjetiva no “eu penso”, não haveria "inconsistência existencial" se não aceitássemos a existência do sujeito diante da asserção "eu existo”, porque entre o sujeito do enunciado e o sujeito da enunciação há divergência, não identidade: o "eu” do "eu existo” reside noutro lugar que não aquele em que se processa um pensamento. A implicação "quaseexistencial" (devido a seu caráter volátil) incide sobre algo radicalmente diferente desse eu que pretende estar afirmando sua própria existência — incide sobre o sujeito da enunciação, que nunca se atualiza no enunciado. Sua consequência ontológica não exige a passagem entre as duas partes da sentença "eu penso, eu existo”, mas o isolamento de sua primeira parte. A diferenciação entre sujeito do 
enunciado e sujeito da enunciação transforma a repetição do eu na sentença em mero caso de homonímia, e este é, aliás, o próprio ponto de partida da análise lacaniana do cogito. Não se trata aí da passagem do "eu penso" ao "eu existo", mas da passagem do "eu penso" à existência do sujeito do inconsciente incapaz de transpor sua própria existência para um enunciado, devido à equivocidade como característica definidora do significante.

Assim, embora tanto Hintikka quanto Lacan assumam a necessidade de remeter o ato da representação a algo além do nível da representação, havendo em ambos uma qualificação performativa do cogito, suas conclusões são diferenciadas. Enquanto, para o primeiro, a força do argumento cartesiano concentra-se na proposição "eu existo", porquanto saberíamos a quem este “eu” encontrar-seia referido, para o psicanalista, essa é, justamente, a proposição ameaçada de invalidação, e tal saber, aquele que deve ser questionado.

Obsta-se ao prosseguimento da discussão na medida que a estratégia em pauta encontra-se fundamentada na quebra - para todos os efeitos, crítica - do uso do pronome "eu”. Certamente, do ponto de vista de uma teoria que assume a hipótese do inconsciente como estrutura simbólica determinante do imaginário, a afirmação de que tal pronome "inevitavelmente se refere a quem quer que esteja falando” (HINTIKKA, 1962, p.14) não seria considerada como nada mais do que uma declaração ingênua. Ora, é exatamente este o ponto contestado pela suposição da Spaltung do sujeito. Assim, o comentário lacaniano do cogito não só não converge com o de Hintikka, como fornece elementos para sua invalidação, ao apresentar uma clara alternativa de interpretação: o sujeito do ato não precisa ser necessariamente aquele que se reconhece no pronome atualizado no enunciado. Por aí, vemos que aquilo que está em jogo na distância que separa os dois comentários é nada mais, nada menos, do que o teor especificamente psicanalítico de um deles, cuja força reflexiva se alimenta da filosofia não apenas como interlocução para a construção de uma teoria própria, mas também para, no meio do percurso, questionar seu cerne constitutivo. Todavia, embora Lacan atravesse Descartes para subverter seus objetivos, embora recorra à filosofia para posteriormente se proclamar antifilósofo, embora se insira na discussão ontológica para fundar uma "pré-ontologia” (LACAN, 1964/1973, p.31), sempre resta que rir da filosofia não é menos filosofar.

Recebido em 17/9/2007. Aprovado em 11/6/2008. 


\section{REFERÊNCIAS}

BEYSSADE, J.-M. (1972/1974) “Descartes”, in CHÂTELET, F. História da filosofia, v.3: A filosofia do novo mundo. Rio de Janeiro: Zahar.

DESCARTES, R. (1641/1983) “Meditações”, in Os pensadores. São Paulo: Abril Cultural.

HINTIKKA, J. (1962) Cogito, ergo sum: inference or performance? In The philosophical review, v. 71, n. 1. New York: Cornell University, p.3-32.

KANT, I. (1787/1985) Crítica da razão pura. 2 ed. Lisboa: Fundação Calouste Gulbenkian.

LACAN, J. (1957/1966) “L’instance de la lettre dans l'inconscient ou la raison depuis Freud”, in Écrits. Paris: Seuil.

_. (1960/1966) "Position de l'inconscient", in Écrits. Paris: Seuil.

(1964/1973) Le Séminaire livre XI, Les quatre concepts fondamentaux de la psychanalyse. Paris: Seuil (Points).

(1966-67) La logique du fantasme — Séminaire 1966-1967. Inédito.

LEVY, L. (2004) "Ainda o cogito: uma reconstrução do argumento da segunda meditação”, in ÉVORA, F. et al. (org.) Lógica e ontologia — Ensaios em homenagem a Balthazar Barbosa Filho. São Paulo: Discurso.

LONGUENESSE, B. (2006) “Cogito kantien et cogito cartésien”, in FICHANT, M. \& MARION, J.-L. (orgs.) Descartes en Kant. Paris: PUF.

PARIENTE, J.-C. (1987) “Problèmes logiques du cogito", in GRIMALDI, N. \& MARION, J.-L. (orgs.) Le discours et sa méthode. Paris: PUF.

(1999) "La première personne et as fonction dans le cogito", in ONG-VAN-CUNG, K. (org.) Descartes et la question su sujet. Paris: PUF.

SÁ, R. de. (2002) A ação do cogito como uma subversão da relação entre saber e ato. Sofia - revista de filosofia, v.VIII, n. 9 e 10, Vitória/ES: Ufes, p.247-269.

SAFATLE, V. (2000) A ilusão da transparência: sobre a leitura lacaniana do cogito cartesiano. Ágora — Estudos em teoria psicanalítica, v.III, n.1, Rio de Janeiro: UFRJ, p.59-76.

SARTRE, J.-P. (1936/1994) A transcendência do ego. Lisboa: Colibri.

Léa Silveira Sales

lea_silveira@uol.com.br 